\title{
Article \\ Plant-Derived Lactobacillus paracasei IJH-SONE68 Improves Chronic Allergy Status: A Randomized, Double-Blind, Placebo-Controlled Clinical Trial
}

\author{
Masafumi Noda ${ }^{1}$, Keishi Kanno ${ }^{2,3}$, Narandalai Danshiitsoodol ${ }^{1}$ (D) Fumiko Higashikawa ${ }^{1}$ and \\ Masanori Sugiyama 1,3,*
}

check for

updates

Citation: Noda, M.; Kanno, K.; Danshiitsoodol, N.; Higashikawa, F.; Sugiyama, M. Plant-Derived Lactobacillus paracasei IJH-SONE68 Improves Chronic Allergy Status: A Randomized, Double-Blind, Placebo-Controlled Clinical Trial. Nutrients 2021, 13, 4022. https:// doi.org/10.3390/nu13114022

Academic Editor: Stephen Ives

Received: 14 October 2021

Accepted: 9 November 2021

Published: 11 November 2021

Publisher's Note: MDPI stays neutral with regard to jurisdictional claims in published maps and institutional affiliations.

Copyright: (c) 2021 by the authors. Licensee MDPI, Basel, Switzerland. This article is an open access article distributed under the terms and conditions of the Creative Commons Attribution (CC BY) license (https:/ / creativecommons.org/licenses/by/ $4.0 /)$.
1 Department of Probiotic Science for Preventive Medicine, Graduate School of Biomedical and Health Sciences, Hiroshima University, Kasumi 1-2-3, Minami-ku, Hiroshima 734-8551, Japan; bel@hiroshima-u.ac.jp (M.N.); naraa@hiroshima-u.ac.jp (N.D.); fumiko@hiroshima-u.ac.jp (F.H.)

2 Department of General Internal Medicine, Hiroshima University Hospital, Kasumi 1-2-3, Minami-Ku, Hiroshima 734-8551, Japan; kkanno@hiroshima-u.ac.jp

3 Department of Clinical Pharmaceutical and Therapeutics, Hiroshima University, Kasumi 1-2-3, Minami-ku, Hiroshima 734-8551, Japan

* Correspondence: sugi@hiroshima-u.ac.jp; Tel.: +81-(82)-257-5280

\begin{abstract}
We have recently demonstrated that the exopolysaccharides (EPSs) produced by a plantderived lactic acid bacterium, Lactobacillus paracasei IJH-SONE68, prevent and ameliorate allergic reaction on contact in dermatitis model mice. In the present study, we conducted a clinical trial using a capsule containing spray-dried powder from pineapple juice broth fermented with the LAB strain as an experimental diet. The clinical trial was conducted as a double-blind and placebo-controlled randomized comparative study from May 2019 to July 2021. Males and females between the ages of 21 and 70 who experience chronic allergies participated in the study. Sixty subjects were instructed to orally take a capsule containing the IJH-SONE68 powder or placebo, every day for 12 weeks. After the clinical trial was over, the scores based on subjects' self-assessment of allergic status were significantly improved in the intervention group, as compared with the placebo group. Some serum biochemicals associated with inflammation response were also significantly improved by intake of the experimental diet. In conclusion, the IJH-SONE68-derived EPS improves chronic allergy status in humans and is expected to decrease their inconvenience.
\end{abstract}

Keywords: Lactobacillus paracasei; chronic allergy; clinical trial; plant-derived lactic acid bacterium; anti-inflammation

\section{Introduction}

Allergic diseases are immunoglobulin E ( $\mathrm{IgE}$ )-mediated type I inflammatory disorders, including allergic rhinitis [1,2]. The major symptoms of allergic rhinitis are sneezing, nasal congestion, and lacrimation caused by complex allergen-driven mucosal inflammations, and the increased inflammatory mediators lead to sensory nerve activation, plasma leakage, and congestion [3,4]. The prevalence of these diseases in the USA ranges from 9 to $42 \%$, and in the UK, it reaches $26 \%$ in adults $[1,5]$. An epidemiological study in Japan revealed that the prevalence of allergic rhinitis markedly increased from 29.8 to $39.4 \%$, between 1998 and 2008 [6]. Allergic rhinitis is manageable with appropriate treatment but resists cure; thus, the treatment is aimed at alleviating symptoms and removing difficulties to improve patients' quality of life (QOL) [6].

Lactic acid bacteria (LABs) is a generic name given to Gram-positive bacteria that produce a large amount of lactic acid [7]. The LABs are generally non-pathogenic and many strains of them produce functional substances that have health benefits for humans $[8,9]$. Therefore, some beneficial LAB strains are regarded as probiotics, which are defined as, 
living microorganisms conferring health benefits to hosts when consumed in adequate amounts [10].

We have isolated many kinds of LABs from natural sources, especially from raw plants, including fruits and medicinal herbs. Through randomized clinical trials, we have found in our established plant-derived LAB library of more than 1000 strains, some useful ones for preventive medicine, such as for improving constipation, obesity, and hepatic dysfunction [11-13]. Furthermore, we have confirmed that some of the isolates produce exopolysaccharides (EPSs) outside cells [14-17]. Interestingly, EPSs have been found to inhibit the catalytic activity of hyaluronidase (EC 3.2.1.35), which catalyzes the hydrolysis of the main extracellular matrix constituent, hyaluronic acid. Under inflammatory conditions, the hydrolysis of hyaluronic acid makes inflammation worse [18-21]. The inhibitory phenomenon against hyaluronidase, as some anti-allergic agents, correlates with the inhibition of IgE-mediated histamine release from mast cells during inflammatory reactions [22,23].

One of the EPS-producing strains, Lactobacillus ( $L b$.) paracasei IJH-SONE68, was isolated from a fig leaf. Our previous study revealed that the IJH-SONE68-derived neutral EPS has a novel structure, which mainly consists of $\alpha$-1,6-linked chains made of $\mathrm{N}$-acetylglucosamine [17]. In addition, the IJH-SONE68-derived EPSs inhibit the catalytic activity of hyaluronidase, as well as some commercially used anti-allergic and anti-inflammation agents $[15,17,24,25]$. Our recent animal experiments also showed that IJH-SONE68-derived EPSs prevent and improve picryl chloride-induced contact dermatitis and dextran sulfate sodium (DSS)-induced ulcerative colitis on model mice, by repressing the accelerated expression of interleukin (IL)-4 and the serum IgE level [26] and by reducing the MIP-2 expression [27], respectively. Therefore, in the present study, we aim to show that IJH-SONE68-derived EPSs improve allergic conditions by conducting a clinical trial involving subjects with perennial allergy symptoms, which may be accompanied by chronic inflammation.

\section{Materials and Methods}

\subsection{Subjects}

Healthy volunteers who live in the Hiroshima area of Japan and who are between 20 and 70 years old, were recruited through a series of advertisements. The inclusion criteria were that subjects must be healthy males or females who have at least once (1) a score of 8 to 20 on the self-assessment questionnaire for allergic symptoms (Table 1) and (2) a score of 40 or above for the visual analogue scale (VAS) value, indicating difficulty in daily life activities (Figure 1). The items and scores were designed according to the criteria previously developed in guidelines $[6,28]$. The exclusion criteria were applied to volunteers who (1) have allergic hypersensitivity to pineapple; (2) use regular medication; (3) are pregnant or breastfeeding; (4) take medicines, supplements, or functional foods that may affect allergic symptoms; or (5) participated in any other clinical trials within 3 months of the commencement of this study. Written informed consent was obtained from each participant before the start of the trial.

\section{VAS for difficulty in activities of daily life}

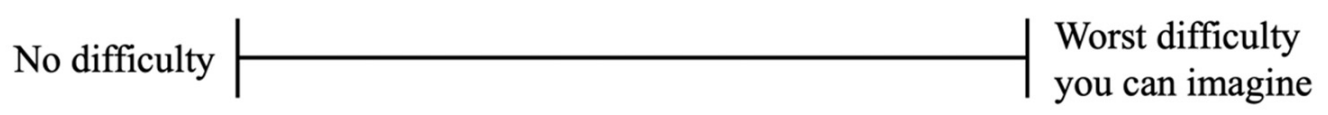

Figure 1. VAS for difficulty in daily life activities for self-assessment questionnaire (100 mm width, without scale indication). 
Table 1. Questionnaire items for self-assessment and scoring characteristics.

\begin{tabular}{|c|c|c|c|c|c|c|}
\hline \multirow[b]{2}{*}{ Score } & \multicolumn{6}{|c|}{ Items } \\
\hline & $\begin{array}{l}\text { Frequency of } \\
\text { Sneezing } \\
\text { (Average } \\
\text { Times/Day) }\end{array}$ & $\begin{array}{c}\text { Frequency of } \\
\text { Blowing } \\
\text { (Average } \\
\text { Times/Day) }\end{array}$ & $\begin{array}{c}\text { Nasal } \\
\text { Congestion }\end{array}$ & Itchy Eyes & Watery Eyes & Head Dullness \\
\hline 0 & No sneezing & No sneezing & None of the time & None of the time & None of the time & None of the time \\
\hline 1 & $1-5$ & $1-5$ & $\begin{array}{l}\text { A little of the time } \\
\text { (without mouth-breathing) }\end{array}$ & Mild & Mild & Mild \\
\hline 2 & $6-10$ & $6-10$ & $\begin{array}{l}\text { Some of the time } \\
\text { (with mouth-breathing) }\end{array}$ & Moderate to severe & Moderate to severe & Moderate to severe \\
\hline 3 & $11-20$ & $11-20$ & $\begin{array}{l}\text { Most of the time } \\
\text { (with mouth-breathing) }\end{array}$ & Severe & Severe & Severe \\
\hline 4 & 21 or more & 21 or more & $\begin{array}{c}\text { All of the time } \\
\text { (with mouth-breathing) }\end{array}$ & $\begin{array}{l}\text { Very } \\
\text { severe }\end{array}$ & $\begin{array}{l}\text { Very } \\
\text { severe }\end{array}$ & $\begin{array}{l}\text { Very } \\
\text { severe }\end{array}$ \\
\hline
\end{tabular}

\subsection{Study Capsules and Placebo}

We delegated the production of placebo and test capsules to SAKURAO Brewery and Distillery Co., Ltd., Japan. The test capsules contained heat-killed IJH-SONE68strain powder and dextrin, whereas the placebo capsules contained dextrin only. The IJH-SONE68 strain was cultured in pineapple juice and then the cultured broth was heattreated before applying a spray dryer. In total, $1040 \mathrm{mg}$ of IJH-SONE68 powder, which contained approximately $5.0 \times 10^{5}$ cells, was used to fill four separate capsules. The placebo capsule contained the same amount of dextrin.

\subsection{Study Design}

This trial was conducted at Hiroshima University (Hiroshima, Japan) from May 2019 to July 2021 using a double-blind, randomized, placebo-controlled parallel-group study. Eligible subjects who met the criteria were enrolled and stratified according to their score on the self-assessment questionnaire ( $12 \leq$ or less) and serum IgE concentration ( $251 \leq \mathrm{IU} / \mathrm{mL}$ or less), then assigned to the IJH-SONE68 or placebo group using the blocked randomization method in a 1:1 allocation ratio with a block size of 4 . The allocation table was generated using Microsoft Excel software. Randomization assignments were carried out by non-clinical staff, with no analytical involvement in the present trial. The subjects and outcome assessors were blinded to the assignment information.

The subjects were instructed to take 4 capsules of either the IJH-SONE68 or placebo daily at any time within the day for 12 weeks. They were also directed to keep their ordinary dietary habitats and not to donate blood during the trial period. The subjects were provided with daily dated record forms throughout the trial period, to make a record of their consumption of capsules and their health conditions. The forms also contained a daily answer sheet for a self-assessment questionnaire and VAS value. Adverse events that newly emerged or worsened after intervention were evaluated when those grades shifted higher, according to the Common Terminology Criteria for Adverse Events version 5.0 (CTCAE v5.0).

The primary outcomes of the present study were, changes in the self-assessment questionnaire and VAS value, and the secondary outcomes were, changes in the serum total $\operatorname{IgE}$ and specific IgE (for 2 types of house dust, Gramineae pollen, weed pollen, animal dander, and fungi) levels. The subjects visited Hiroshima University for physical examinations (every 4 weeks), serum total IgE measurements (every 4 weeks), answering the self-assessment questionnaire and assigning a VAS value (every 4 weeks), and serum specific IgE and biochemical measurements and urinalysis (at 12 weeks). Blood samples were obtained after a $9 \mathrm{~h}$ overnight fast. Body fat percentage was measured using a body composition analyzer (BC-118E, Tanita, Tokyo, Japan). Blood pressure was measured according to the Japanese Society of Hypertension Guidelines for the Management of Hypertension 2019 (JSH2019) [29]. 
The protocol of the present clinical trial was approved by the Ethics Committee of Hiroshima University (approval no. C-266) and performed according to the guidelines of the Helsinki Declaration. This trial was registered in the University Hospital Medical Information Network Clinical Trials Registry (UMIN-CTR), ID: UMIN000036317, on 11 March 2019.

\subsection{Statistical Analysis}

The sample size in each group in the present study was calculated as 46 , to detect $10 \%$ difference with an estimated S.D. of $20 \%$ for total $\mathrm{IgE}$, assuming $80 \%$ power and a two-sided significance level of 0.05 using two-sample $t$-test. The difference and S.D. for sample size estimation were performed on the basis of the data from our previous animal study [26]. The obtained data were analyzed according to the intention-to-treat principle, and the multiple-imputation method was applied to missing data [30]. For each outcome, 20 multiple-imputed data sets were generated and the resultant analyses were combined. The analysis of covariance (ANCOVA) was applied to changes from the baseline for primary outcomes and serum total IgE using each baseline value as a covariate. The baseline characteristics were compared using the unpaired Student's $t$-test. Statistical analysis for changes in each item on the questionnaire was done using the Mann-Whitney $\mathrm{U}$ test, since the results did not show a normal distribution. All statistical analyses were performed using IBM SPSS Statistics $17.0 \mathrm{~J}$ for Windows (IBM Japan, Tokyo, Japan).

\section{Results}

\subsection{Recruitment of Subjects}

Recruitment for the present trial is summarized in Figure 2. Among 264 applicants who were interested in the trial, 175 did not satisfy the inclusion criteria or canceled their application. After participating in the explanatory meeting, 60 eligible subjects (aged 21-70) were enrolled in the study and were randomly divided into two groups, the IJH-SONE68intake group or the placebo group.

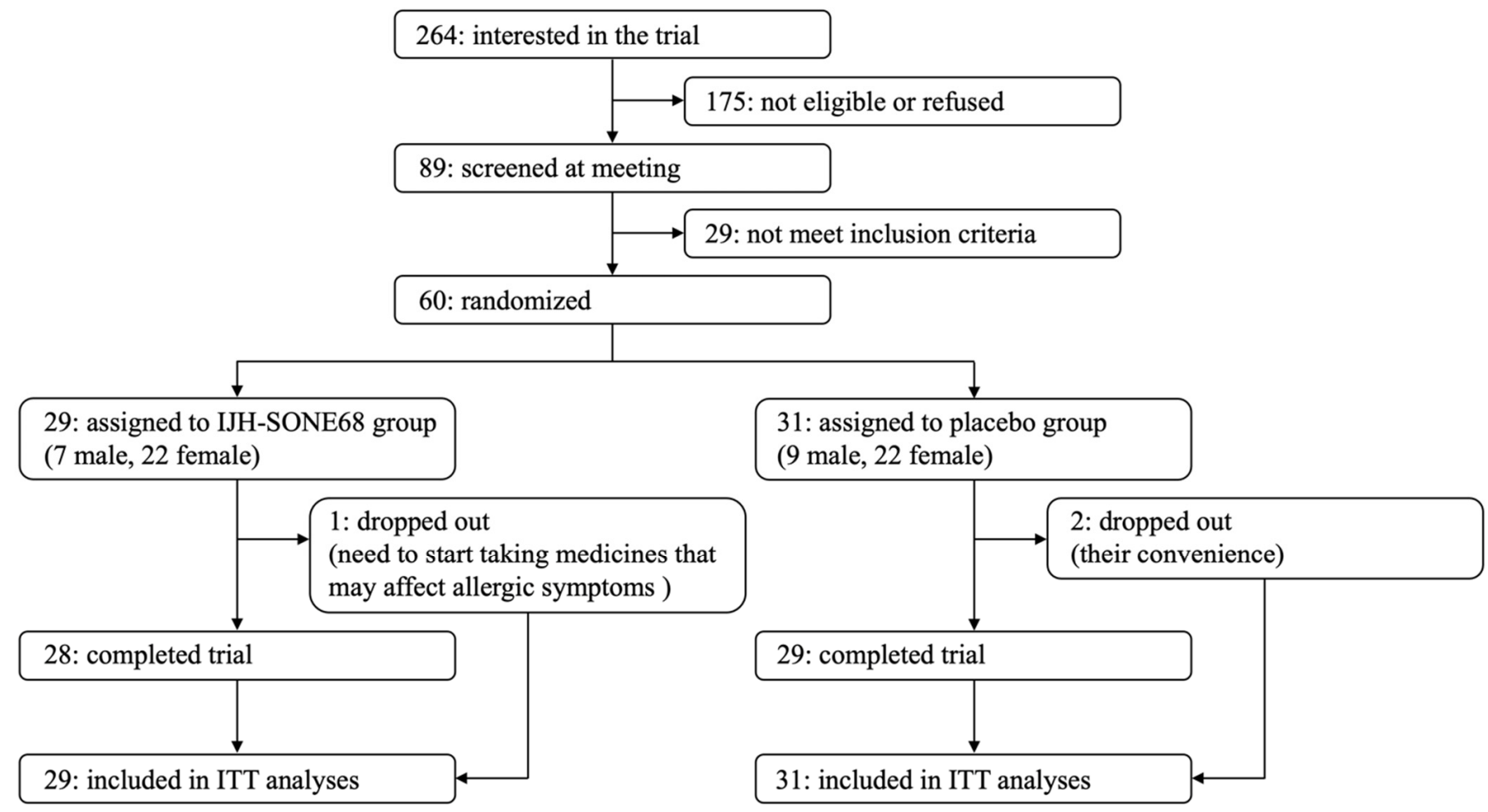

Figure 2. Flow diagram of subjects in the study. 
Based on the scheduled deadline and the limited financial resources, it was difficult to recruit subjects in a short period of time with prevention of the spread of COVID-19. Therefore, this study was unavoidably completed before the original registration goal was achieved $(n=100)$. The baseline characteristics of the subjects are summarized in Table 2. Between two groups, there were no significant differences in the listed items. During the trial period, 3 subjects dropped out from the study because of the need to start taking medicines that may affect allergic symptoms (1 in the IJH-SONE68 group) and their convenience ( 2 in the placebo group). The remaining 57 subjects completed the study (95\% rate). The data obtained from all subjects were analyzed after filling in the missing data by the multiple imputation method. The average compliance rates for taking capsules daily were $94.9 \%$ and $95.6 \%$ in the IJH-SONE68 and placebo groups, respectively. The blinding success confirmed by the questionnaire resulted in $35.0 \%$ correct, $23.3 \%$ incorrect, and $40.0 \%$ "cannot judge" answers.

Table 2. Baseline characteristics of the subjects.

\begin{tabular}{cccc}
\hline & IJH-SONE68 $(\boldsymbol{n}=\mathbf{2 9})$ & Placebo $(\boldsymbol{n}=\mathbf{3 1})$ & $\boldsymbol{p}$ Value \\
\hline Age (years) & $51.6 \pm 14.4$ & $54.8 \pm 10.5$ & 0.331 \\
Male & $53.0 \pm 17.4(n=7)$ & $56.3 \pm 12.0(n=9)$ & 0.674 \\
Female & $51.1 \pm 13.8(n=22)$ & $54.2 \pm 10.1(n=22)$ & 0.408 \\
Height (cm) & $160.1 \pm 9.6$ & $160.0 \pm 7.7$ & 0.834 \\
Body weight (kg) & $55.4 \pm 15.6$ & $56.4 \pm 12.4$ & 0.796 \\
Systolic blood pressure (mmHg) & $110.1 \pm 15.5$ & $118.6 \pm 16.9$ & 0.067 \\
Diastolic blood pressure (mmHg) & $67.8 \pm 11.2$ & $73.5 \pm 12.3$ & 0.067 \\
\hline
\end{tabular}

Data are indicated as mean \pm S.D. $p$ values are calculated using unpaired Student's $t$-test.

\subsection{Effects of IJH-SONE68 on Primary Outcomes}

The changes in primary outcomes, which were the self-assessment questionnaire scores and the VAS values (Table 1 and Figure 1), during the trial period are summarized in Table 3. Although the average self-assessment questionnaire score in both groups decreased, there was a significant difference between the changes in questionnaire scores $(p=0.008)$. Likewise, the average VAS value in both groups decreased considerably, but changes in the value were not significant $(p=0.380)$.

Table 3. Changes in primary outcomes in the study.

\begin{tabular}{cccc}
\hline & IJH-SONE68 $(\boldsymbol{n}=\mathbf{2 9 )}$ & Placebo $(n=31)$ & $p$ Value \\
\hline Summary of & & & 0.008 \\
self-questionnaire score & $10.1 \pm 0.6$ & $9.5 \pm 0.3$ & \\
Baseline & $-3.6 \pm 0.5$ & $-1.9 \pm 0.5$ & 0.380 \\
Change at 12 week & & & \\
VAS value & $52.3 \pm 2.7$ & $57.4 \pm 3.4$ & \\
Baseline & $-17.6 \pm 3.6$ & $-13.1 \pm 3.5$ & \\
Change at 12 week & &
\end{tabular}

Data are indicated as mean \pm S.E. $p$ values between IJH-SONE68 and placebo groups are calculated by ANCOVA using each baseline value as a covariate.

The score changes in each item of the self-assessment questionnaire were also compared (Table 4). Although the average scores for each of the six items decreased in both groups, the scores for head dullness, watery eyes, and frequency of nose-blowing and sneezing in the IJH-SONE68 group decreased, more than those in the placebo group $(p<0.05)$. 
Table 4. Changes in each item of the self-assessment questionnaire.

\begin{tabular}{|c|c|c|c|}
\hline & IJH-SONE68 $(n=29)$ & Placebo $(n=31)$ & $p$ Value \\
\hline Frequency of sneezing & & & $<0.05$ \\
\hline Baseline & $1.9 \pm 0.2$ & $1.7 \pm 0.2$ & \\
\hline 12 week & $1.2 \pm 0.2$ & $1.5 \pm 0.1$ & \\
\hline Frequency of blowing & & & $<0.05$ \\
\hline Baseline & $2.0 \pm 0.2$ & $2.0 \pm 0.2$ & \\
\hline 12 week & $1.3 \pm 0.2$ & $1.7 \pm 0.2$ & \\
\hline Nasal congestion & & & - \\
\hline Baseline & $1.8 \pm 0.1$ & $1.9 \pm 0.2$ & \\
\hline 12 week & $1.3 \pm 0.2$ & $1.4 \pm 0.2$ & \\
\hline Itchy eyes & & & - \\
\hline Baseline & $1.8 \pm 0.2$ & $1.5 \pm 0.1$ & \\
\hline 12 week & $1.0 \pm 0.2$ & $1.1 \pm 0.1$ & \\
\hline Watery eyes & & & $<0.05$ \\
\hline Baseline & $1.1 \pm 0.1$ & $0.9 \pm 0.1$ & \\
\hline 12 week & $0.6 \pm 0.1$ & $0.9 \pm 0.1$ & \\
\hline Head dullness & & & $<0.05$ \\
\hline Baseline & $1.6 \pm 0.2$ & $1.4 \pm 0.2$ & \\
\hline 12 week & $1.1 \pm 0.2$ & $1.1 \pm 0.2$ & \\
\hline
\end{tabular}

Data are indicated as mean \pm S.E. $p$ values between IJH-SONE68 and placebo groups are calculated by the Mann-Whitney $U$ test.

\subsection{Effects of IJH-SONE68 on Secondary Outcomes}

The serum total IgE decreased slightly in the IJH-SONE68 group; however, there was no significant difference between the two groups for changes in the total IgE (Table 5). Although the decrease in serum specific IgE was also assessed as a secondary outcome, there were not enough subjects who were positive for each of the six specific IgE values, according to the semi-quantitative classification (Table 6 and Figure 3).

Table 5. Changes in serum total $\operatorname{IgE}$ in the study.

\begin{tabular}{cccc}
\hline & IJH-SONE68 $(\boldsymbol{n}=\mathbf{2 9 )}$ & Placebo $(\boldsymbol{n}=\mathbf{3 1})$ & $\boldsymbol{p}$ Value \\
\hline Total IgE $\left(\log _{10} \mathrm{IU} / \mathrm{mL}\right)$ & $1.87 \pm 0.10$ & $1.90 \pm 0.10$ & 0.361 \\
Baseline & $-0.004 \pm 0.019$ & $0.021 \pm 0.019$ & \\
Change at 12 week &
\end{tabular}

Data are indicated as mean \pm S.E. $p$ values between IJH-SONE68 and placebo groups are calculated by ANCOVA using each baseline value as a covariate.

Table 6. Classification of specific IgE levels.

\begin{tabular}{ccc}
\hline Class & Specific IgE Titer $\left(\mathbf{U}_{\mathbf{A}} / \mathbf{m L}\right)$ & Quantitative Analysis \\
\hline 0 & $<0.35$ & Negative \\
1 & 0.35 to $<0.70$ & Boundary \\
2 & 0.70 to $<3.50$ & Positive \\
3 & 3.50 to $<17.5$ & Positive \\
4 & 17.5 to $<50.0$ & Positive \\
5 & 50.0 to $<100$ & Positive \\
6 & $100<$ & Positive \\
\hline
\end{tabular}

\subsection{Monitoring the Adverse Effects}

Physical examinations and other serum parameters were also monitored to detect adverse effects of IJH-SONE68 intake. According to the CTCAE v5.0, there were no significant differences in adverse events possibly related to the study design, between the IJH-SONE68 and placebo groups (Table 7). In addition, in the IJH-SONE68 group, the average parameters for serum aspartate aminotransferase (AST), alanine aminotransferase (ALT), alkaline phosphatase (ALP), and cholinesterase (ChE), were decreased from the baseline, and the changes in those parameters were significant when compared with 
the placebo group (Supplementary Table S1). No abnormal change was observed in the urinalysis data throughout this clinical trial.

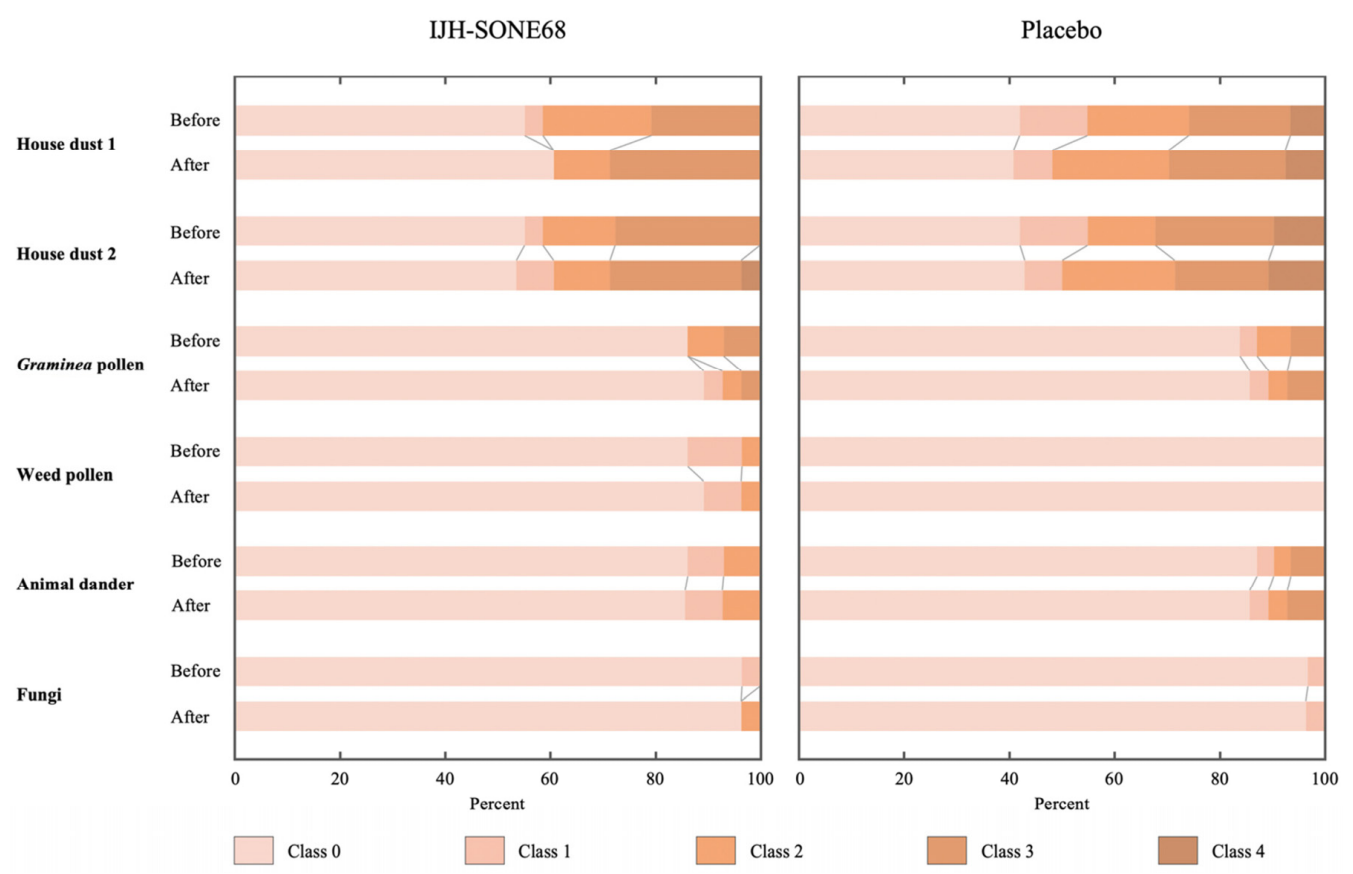

Figure 3. Stacked bar plot describing the specific IgE classifications of subjects for each of the 6 allergens before and after treatment.

Table 7. Number of subjects who show adverse events that were possibly related to the study design or treatments.

\begin{tabular}{|c|c|c|c|}
\hline & $\begin{array}{c}\text { IJH-SONE68 } \\
(n=29)\end{array}$ & $\begin{array}{l}\text { Placebo } \\
(n=31)\end{array}$ & $p$ Value \\
\hline Anemia & & & 0.229 \\
\hline Grade 1 & $2(7 \%)$ & 0 & \\
\hline Blood bilirubin increased & & & 0.942 \\
\hline $\begin{array}{ll}\text { Grade } 1\end{array}$ & 0 & $2(6 \%)$ & \\
\hline $\begin{array}{c}\text { Blood lactate dehydrogenase } \\
\text { increased }\end{array}$ & & & 0.355 \\
\hline Grade 1 & $1(3 \%)$ & $4(13 \%)$ & \\
\hline Cholesterol high & & & 0.518 \\
\hline Grade 1 & $12(41 \%)$ & $16(52 \%)$ & \\
\hline Grade 2 & $1(3 \%)$ & 0 & \\
\hline Creatinine increased & & & 1.000 \\
\hline Grade 1 & $2(7 \%)$ & $2(6 \%)$ & \\
\hline Weight gain & & & 0.737 \\
\hline Grade 1 & 0 & $1(3 \%)$ & \\
\hline Grade 2 & $1(3 \%)$ & 0 & \\
\hline White blood cell decreased & & & 0.666 \\
\hline Grade 1 & $3(10 \%)$ & $2(6 \%)$ & \\
\hline Hyperglycemia & & & 0.148 \\
\hline Grade 1 & $2(7 \%)$ & $7(23 \%)$ & \\
\hline Hypertriglyceridemia & & & 0.355 \\
\hline Grade 1 & $1(3 \%)$ & $4(13 \%)$ & \\
\hline Hyperuricemia & & & 1.000 \\
\hline Grade 1 & $1(3 \%)$ & $2(6 \%)$ & \\
\hline Hypoalbuminemia & & & 1.000 \\
\hline Grade 1 & 0 & $1(3 \%)$ & \\
\hline Hypertension & & & 0.581 \\
\hline Grade 1 & $7(24 \%)$ & $9(29 \%)$ & \\
\hline Grade 2 & $2(7 \%)$ & $4(13 \%)$ & \\
\hline
\end{tabular}




\section{Discussion}

Different from seasonal allergies like pollinosis, which is caused by pollen allergens, perennial allergies cause chronic symptoms that appear year-round or intermittently. Therefore, perennial allergies considerably decrease the QOL for those patients. Common allergens that account for perennial allergy symptoms are indoor allergens, such as house dust mites (mostly), animal dander, cockroaches, and fungi [31,32]. A number of symptoms, including head dullness, nasal congestion, runny nose, watery and itchy eyes, and sneezing, are expected to be present in a person who has perennial allergies as well as in those with seasonal allergies. In the present trial, the self-assessment questionnaire answers regarding those symptoms, are scored and analyzed as primary outcomes. As shown in Table 4, the results indicate that the IJH-SONE68 capsule significantly improved some of the symptoms. More detailed changes in the composition of questionnaire scores before and after the intake of IJH-SONE68 or placebo capsules, are shown in Figure 4. Regardless of group, the questionnaire scores decreased for each item throughout the 12 weeks of treatment, especially for frequency of nose blowing and sneezing. On the other hand, no significant differences were observed between the groups in the other primary outcome, the VAS value, indicating that the value might reflect other minor factors in addition to the six items asked in the questionnaire.

IJH-SONE68

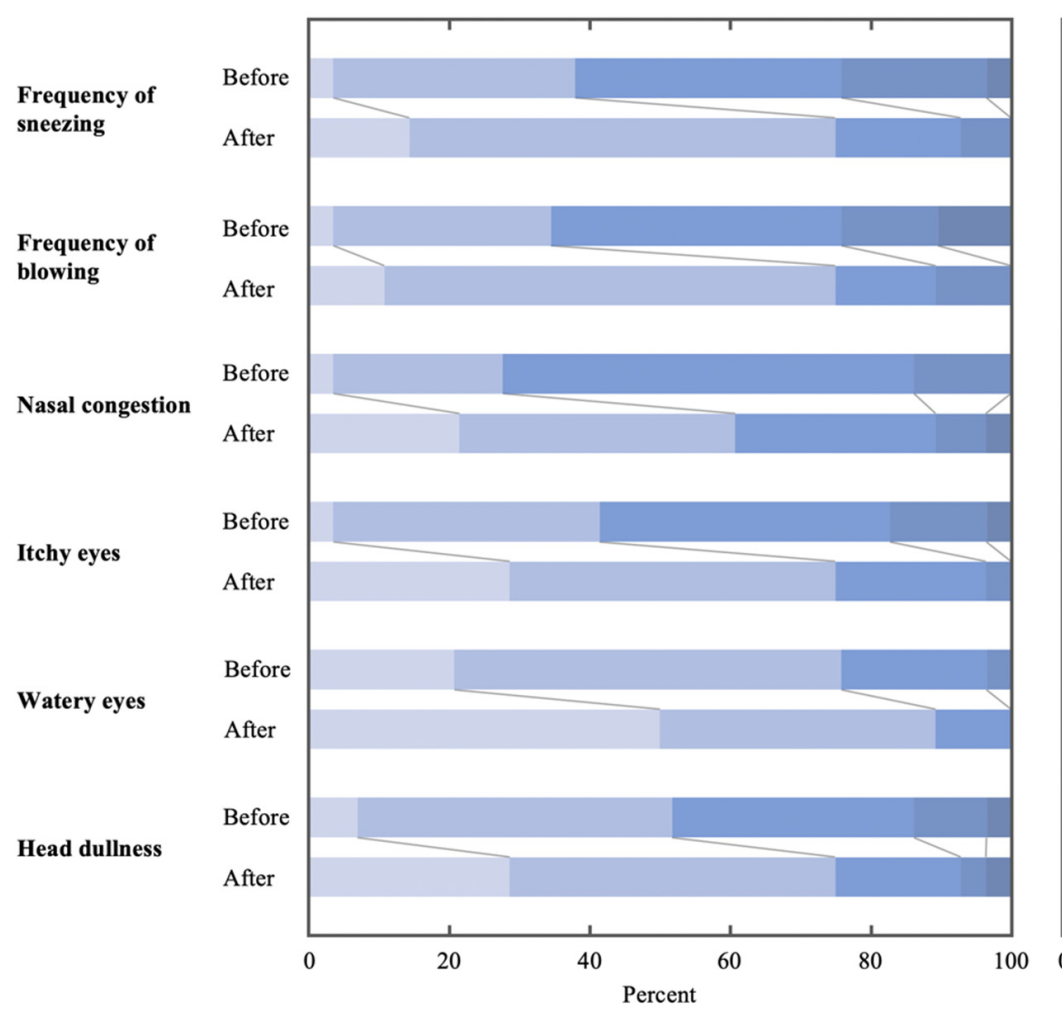

Score 0

Score 1
Score 2

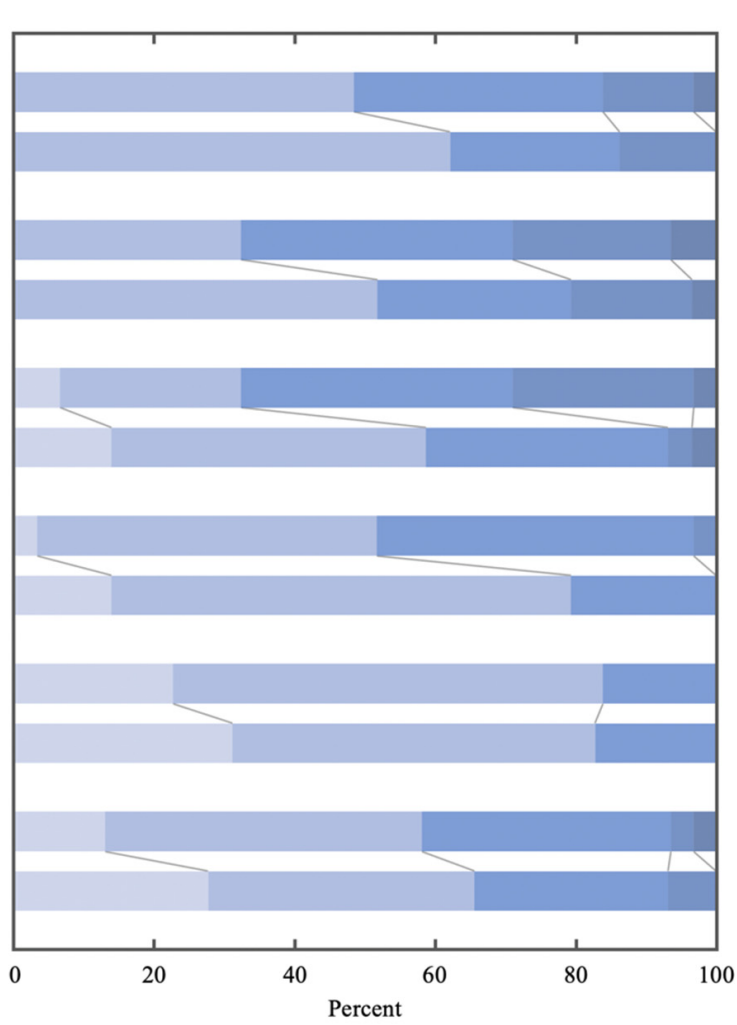

Score 3
Placebo

Figure 4. Stacked bar plot describing the scores provided by subjects in the self-assessment questionnaire for each of the 6 items before and after treatment.

Previously, we showed that the IJH-SONE68-derived EPSs significantly decrease the accelerated serum IgE level and the expression of IL-4 mRNA, in the contact dermatitis model mice [26]. As a preliminary experiment, we also confirmed the improving effect of the IJH-SONE68 strain in the animal model of immediate hypersensitivity, using active cutaneous anaphylaxis model mice [33,34]. Allergic rhinitis is one of the common allergic disorders, which is classified as an immediate allergy [6]. In this allergy type, the allergens 
promote the proliferation of T helper 2 (Th2) cell, resulting in IL-4 release, followed by the antigen-specific IgE production. However, no significant difference was observed in the changes in serum total IgE levels between the groups. Although the serum total IgE was measured as a secondary outcome of the result of the previous animal studies [26,34], the baseline serum IgE levels ranged from 5 to $1410 \mathrm{IU} / \mathrm{mL}$ in the subjects, resulting in a biased population structure and biased result. When the subjects with lower IgE levels (less than $251 \mathrm{IU} / \mathrm{mL}$ ) were analyzed using the Mann-Whitney U test, there was a trend difference between the two groups for changes in total $\operatorname{IgE}(p=0.077)$, indicating that the result partially corresponds to data obtained from the animal experiment [26].

Our recent study also showed that the IJH-SONE68-derived EPS prevents and ameliorates inflammatory responses in the DSS-induced ulcerative colitis model mice with significant repression of MIP-2, which is a functional analogue of human IL-8 [27]. The inflammatory cytokine IL-8 has been reported to play an important role during chronic disease progression through binding to IL-8 receptors A and B, located on the neutrophils [35-37]. Although the changes of cytokines were not analyzed in the present study, allergic symptoms of some subjects with high IgE levels ( $251 \mathrm{IU} / \mathrm{mL}$ or more) might become chronic disease. The precise mechanisms of the IJH-SONE68-derived EPS are not clear yet. However, the EPS seems to modulate excessive immune responses, judging from the result obtained by animal experiments [26,27]. Therefore, by affecting not only IgE-mediated allergic reaction, but also chronic inflammation, the IJH-SONE68-derived EPS might improve the self-assessment questionnaire in the subjects.

There were only a few subjects with specific IgE-positive results; therefore, a statistical analysis could not be conducted. As shown in Figure 3, the composition of the specific IgE classification of each item was basically unchanged throughout the trial period. Considering the decreasing trend observed in the lower IgE group, IJH-SONE68 capsule intake might ameliorate allergic responses, nonspecifically.

The amelioration of the self-assessment questionnaire scores seems to be due to the anti-inflammatory effect of the IJH-SONE68-derived EPSs confirmed in previous studies $[26,31,33]$, in addition to the decrease in $\operatorname{IgE}$ level. Although other biochemical measurements, which were monitored to detect adverse effects of IJH-SONE68 intake, were neither primary nor secondary outcomes, serum levels of AST, ALT, ALP, and ChE were significantly improved in the IJH-SONE68 group. AST and ALT catalyze the transamination reaction to generate oxaloacetic acid and pyruvic acids, respectively, which are necessary to run a citric acid cycle. Both enzymes are highly concentrated in the liver, but AST is also widely distributed in the heart, muscles, and kidneys [38]. Therefore, both elevated serum levels reflect cell injury, but the ALT level is more specific to liver damage. ALP is also present in many mammalian tissues and its elevation in serum is correlated with tissue injury, specifically in liver diseases [39]. As described above, those enzymes leak into the blood stream under inflammatory conditions; thus, the IJH-SONE68-derived EPSs might partially ameliorate those serum biochemical parameters. Since those parameters were not paid attention to and were not assigned as inclusion criteria, further trials with suitable subjects will be needed for clarification.

ChE catalyzes the hydrolyzation of choline esters like acetylcholine and the enzyme is synthesized mainly in hepatocytes. A decrease in the ChE level is observed in patients with liver dysfunction, such as cirrhosis; whereas a high serum $\mathrm{ChE}$ level has been reported to be associated with obesity and metabolic syndrome [40-42]. Interestingly, the trend difference between the changes in body fat percentage of the two groups, was observed $(p=0.058)$. Our preliminary study suggested that IJH-SONE68 also has an anti-obesity effect, and therefore, lipid metabolism and fatty liver might be improved during the trial, resulting in the decrease of ALT and ChE. The present study indicated that the IJH-SONE68 strain can be expected to help persons with perennial allergies, to decrease their inconvenience. 


\section{Conclusions}

The oral administration of the spray-dried powder derived from the culture broth of $L b$. paracasei IJH-SONE68, has been shown to significantly improve the scores based on subjects' self-assessment of allergic status in the present clinical study. The present outcome demonstrates that the IJH-SONE68 strain can be expected to help persons with perennial allergies and decrease inconvenience.

Supplementary Materials: The following are available online at https:/ /www.mdpi.com/article/10 $.3390 /$ nu13114022/s1, Table S1: Changes in other monitored parameters in the study.

Author Contributions: Conceptualization, M.N. and M.S.; methodology, M.N., N.D. and F.H.; formal analysis, M.N.; investigation, M.N., N.D. and F.H.; resources, M.S.; data curation, M.N., K.K., N.D. and F.H.; writing—original draft preparation, M.N. and N.D.; writing—review and editing, M.N., K.K., F.H. and M.S.; visualization, M.N.; supervision, K.K. and M.S.; project administration, M.N. and M.S.; funding acquisition, M.S. All authors have read and agreed to the published version of the manuscript.

Funding: This research was funded by Sone Farm Co., Ltd., Shinjuku, Shinjuku-ku, Tokyo 160-0022, Japan.

Institutional Review Board Statement: The study was conducted according to the guidelines of the Declaration of Helsinki, and approved by the Ethics Committee of Hiroshima University (approval no. C-266 at 22 March 2019).

Informed Consent Statement: Informed consent was obtained from all subjects involved in the study.

Data Availability Statement: The data presented in the study are available in article.

Acknowledgments: The comments provided by Associate Editor and two anonymous reviewers greatly improved the clarity of the manuscript.

Conflicts of Interest: The funders had no role in the design of the study; in the collection, analyses, or interpretation of data; in the writing of the manuscript, or in the decision to publish the results.

\section{References}

1. Liva, G.A.; Karatzanis, A.D.; Prokopakis, E.P. Review of rhinitis: Classification, types, pathophysiology. J. Clin. Med. 2021, 10, 3183. [CrossRef]

2. Barnes, P.J. Pathophysiology of allergic inflammation. Immunol. Rev. 2011, 242, 31-50. [CrossRef]

3. Fan, P.S.; Sun, M.J.; Qin, D.; Yuan, C.S.; Chen, X.G.; Liu, Y. Nanosystems as curative platforms for allergic disorder management. J. Mater. Chem. B. 2021, 9, 1729-1744. [CrossRef]

4. Mandhane, S.N.; Shah, J.H.; Thennati, R. Allergic rhinitis: An update on disease, present treatments and future prospects. Int. Immunopharmacol. 2011, 11, 1646-1662. [CrossRef]

5. Settipane, R.A.; Charnock, D.R. Epidemiology of rhinitis: Allergic and nonallergic. Clin. Allergy Immunol. 2007, 19, 23-34.

6. Okubo, K.; Kurono, Y.; Ichimura, K.; Enomoto, T.; Okamoto, Y.; Kawauchi, H.; Suzaki, H.; Fujieda, S.; Masuyama, K.; The Japanese Society of Allergology. Japanese guidelines for allergic rhinitis 2020. Allergol. Int. 2020, 69, 331-345. [CrossRef]

7. Liu, W.; Pang, H.; Zhang, H.; Cai, Y. Biodiversity of lactic acid bacteria. In Bacteria Fundamentals and Practice; Zhang, H., Cai, Y., Eds.; Springer: Heidelberg, Germany, 2014; pp. 103-203.

8. Cotter, P.D.; Ross, P.R.; Hill, C. Bacteriocins—a viable alternative to antibiotics? Nat. Rev. Microbiol. 2013, 11, 95-105. [CrossRef]

9. Adolfsson, O.; Meydani, S.N.; Russell, R.M. Yogurt and gut function. Am. J. Clin. Nutr. 2004, 80, 245-256. [CrossRef]

10. Sanders, M.E. Probiotics: Definition, source, selection, and uses. Clin. Infect. Dis. 2008, 46, S58-S61. [CrossRef]

11. Higashikawa, F.; Noda, M.; Awaya, T.; Nomura, K.; Oku, H.; Sugiyama, M. Improvement of constipation and liver function by plant-derived lactic acid bacteria: A double-blind, randomized trial. Nutrition 2010, 26, 367-374. [CrossRef]

12. Higashikawa, F.; Noda, M.; Awaya, T.; Danshiitsoodol, N.; Matoba, Y.; Kumagai, T.; Sugiyama, M. Antiobesity effect of Pediococcus pentosaceus LP28 on overweight subjects: A randomized, double-blind, placebo-controlled clinical trial. Eur. J. Clin. Nutr. 2016, 70, 582-587. [CrossRef]

13. Higashikawa, F.; Danshiitsoodol, N.; Kanno, K.; Ishida, R.; Tazuma, S.; Sugiyama, M. Lactobacillus plantarum SN13T cells improve hepatic dysfunction and fecal microbiota: A randomized pilot study. Arch. Clin. Biomed. Res. 2020, 4, 605-625. [CrossRef]

14. Yasutake, T.; Kumagai, T.; Inoue, A.; Kobayashi, K.; Noda, M.; Orikawa, A.; Matoba, Y.; Sugiyama, M. Characterization of the LP28 strain-specific exopolysaccharide biosynthetic gene cluster found in the whole circular genome of Pediococcus pentosaceus. Biochem. Biophys. Rep. 2016, 5, 271-299. [CrossRef]

15. Panthavee, W.; Noda, M.; Danshiitsoodol, N.; Kumagai, T.; Sugiyama, M. Characterization of exopolysaccharides produced by thermophilic lactic acid bacteria isolated from tropical fruits of Thailand. Biol. Pharm. Bull. 2017, 40, 621-629. [CrossRef] 
16. Noda, M.; Shiraga, M.; Kumagai, T.; Danshiitsoodol, N.; Sugiyama, M. Characterization of the SN35N strain-specific exopolysaccharide encoded in the whole circular genome of a plant-derived Lactobacillus plantarum. Biol. Pharm. Bull. 2018, 41, 536-545. [CrossRef]

17. Noda, M.; Sugimoto, S.; Hayashi, I.; Danshiitsoodol, N.; Fukamachi, M.; Sugiyama, M. A novel structure of exopolysaccharide produced by a plant-derived lactic acid bacterium Lactobacillus paracasei IJH-SONE68. J. Biochem. 2018, 164, 87-92. [CrossRef]

18. Bourguignon, L.Y.; Wong, G.; Earle, C.A.; Xia, W. Interaction of low molecular weight hyaluronan with CD44 and toll-like receptors promotes the actin filament-associated protein 110-actin binding and MyD88-NFkB signaling leading to proinflammatory cytokine/chemokine production and breast tumor invasion. Cytoskeleton 2011, 68, 671-693. [CrossRef]

19. Jiang, D.; Liang, J.; Noble, P.W. Hyaluronan in tissue injury and repair. Annu. Rev. Cell. Dev. Biol. 2007, 23, 435-461. [CrossRef]

20. Litwiniuk, M.; Krejner, A.; Speyrer, M.S.; Gauto, A.R.; Grzela, T. Hyaluronic acid in inflammation and tissue regeneration. Wounds 2010, 28, 78-88.

21. Turley, E.A.; Noble, P.W.; Bourguignon, L.Y. Signaling properties of hyaluronan receptors. J. Biol. Chem. 2002, $277,4589-4592$. [CrossRef]

22. Yang, C.H.; Srivastava, P.N. Purification and properties of hyaluronidase from bull sperm. J. Biol. Chem. 1975, 250, 79-83. [CrossRef]

23. Kakegawa, H.; Matsumoto, H.; Satoh, T. Activation of hyaluronidase by metallic salts and compound 48/80, and inhibitory effect of anti-allergic agents on hyaluronidase. Chem. Pharm. Bull. 1985, 33, 642-646. [CrossRef]

24. Fujitani, N.; Sakai, S.; Yamaguchi, Y.; Takenaka, H. Inhibitory effects of microalgae on the activation of hyaluronidase. J. Appl. Phycol. 2001, 13, 489-492. [CrossRef]

25. Maeda, Y.; Yamamoto, M.; Masui, T.; Sugiyama, K.; Yokota, M.; Nakagomi, K.; Tanaka, H.; Takahashi, T.; Kobayashi, E. Inhibitory effect of tea extracts on hyaluronidase. Shokuhin Eiseigaku Zashi 1990, 31, 233-237. [CrossRef]

26. Noda, M.; Sultana, N.; Hayashi, I.; Fukamachi, M.; Sugiyama, M. Exopolysaccharide produced by Lactobacillus paracasei IJHSONE68 prevents and improves the picryl chloride-induced contact dermatitis. Molecules 2019, 24, 2970. [CrossRef]

27. Noda, M.; Danshiitsoodol, N.; Kanno, K.; Uchida, T.; Sugiyama, M. The exopolysaccharide produced by Lactobacillus paracasei IJH-SONE68 prevents and ameliorates inflammatory responses in DSS-induced ulcerative colitis. Microorganisms 2021, 9, 2243. [CrossRef]

28. Okuda, M.; Okubo, K.; Gotoh, M.; Okamoto, Y.; Konno, A.; Baba, K.; Ogino, S.; Ishikawa, T.; Takenaka, H.; Soh, N.; et al. Standard questionnaire for QOL of Japanese patients with allergic rhinitis. Allergy 2003, 52, 21-56.

29. Umehara, S.; Arima, H.; Arima, S.; Asayama, K.; Dohi, Y.; Hirooka, Y.; Horio, T.; Hoshide, S.; Ikeda, S.; Ishimitsu, T.; et al. The Japanese Society of Hypertension Guidelines for the Management of Hypertension (JSH 2019). Hypertens. Res. 2019, 42, 1235-1481.

30. Li, P.; Stuart, E.A.; Allison, D.B. Multiple imputation: A flexible tool for handling missing data. JAMA 2015, 314, 1966-1967. [CrossRef]

31. Saleh, H.A.; Durham, S.R. Perennial rhinitis. BMJ 2007, 335, 502-507. [CrossRef]

32. Bush, R.K. Etiopathogenesis and management of perennial allergic rhinitis: A state-of-the-art review. Treat. Respir. Med. 2004, 3, 45-57. [CrossRef] [PubMed]

33. Inagaki, N.; Miura, T.; Nagai, H.; Koda, A. Active cutaneous anaphylaxis (ACA) in the mouse ear. Jpn. J. Pharmacol. 1992, 59, 201-208. [CrossRef] [PubMed]

34. Noda, M.; Sugiyama, M. Studies aiming for the development of medicines to treat inflammatory disorders. Seibutsu-kogaku Kaishi 2021, 99. in press.

35. Waugh, D.J.J.; Wilson, C. The interleukin-8 pathway in cancer. Clin. Cancer Res. 2008, 14, 6735-6741. [CrossRef] [PubMed]

36. Acosta, J.C.; O’Loghlen, A.; Banito, A.; Guijarro, M.V.; Augert, A.; Raguz, S.; Fumagalli, M.; Da Costa, M.; Brown, C.; Popov, N.; et al. Chemokine signaling via the CXCR2 receptor reinforces senescence. Cell 2008, 133, 1006-1018. [CrossRef]

37. Bernhard, S.; Hug, S.; Stratmann, A.E.P.; Erber, M.; Vidoni, L.; Knapp, C.L.; Thomaß, B.D.; Fauler, M.; Nilsson, B.; Nilsson Ekdahl, K.; et al. Interleukin 8 elicits rapid physiological changes in neutrophils that are altered by inflammatory conditions. J. Innate Immun. 2021, 13, 225-241. [CrossRef]

38. Giannini, E.G.; Testa, R.; Savarino, V. Liver enzyme alteration: A guide for clinicians. CMAJ 2005, 172, 367-379. [CrossRef]

39. Sharma, U.; Pai, D.; Prasad, R. Alkaline phosphatase: An overview. Indian J. Clin. Biochem. 2014, 29, 269-278. [CrossRef]

40. Meng, F.; Yin, X.; Ma, X.; Guo, X.D.; Jin, B.; Li, H. Assessment of the value of serum cholinesterase as a liver function test for cirrhotic patients. Biomed. Rep. 2013, 1, 265-268. [CrossRef] [PubMed]

41. Oda, E. Metabolic syndrome: Its history, mechanisms, and limitations. Acta Diabetol. 2012, 49, 89-95. [CrossRef]

42. Oda, E. Associations between serum cholinesterase and incident hyper-LDL cholesterolemia, hypertriglyceridemia and hypoHDL cholesterolemia as well as changes in lipid levels in a health screening population. Atherosclerosis 2015, 241, 1-5. [CrossRef] [PubMed] 